\title{
Socialization Across the Three Stages of the Correctional Services of Canada's Correctional Officer Training Program: An Ethnographic Study
}

\section{Rosemary Ricciardelli a}

\author{
aMemorial University, Newfoundland and Labrador, Canada
}

\section{ABSTRACT}

The current ethnographic study reflects my participation in elements of the three stages of the correctional officer training program (CTP) offered by the Correctional Service of Canada (CSC). Unpacking my experience, I use Van Maanen and Schein (1977) theory of organizational socialization to analyze the formal and informal socialization processes inherent to the structure of the training academy. Thematic reflection on informal socialization processes reveal that the pressures tied to module content and testing reinforce values welcomed by CSC, such as organizational commitment, before the recruit's arrival at the academy. Moreover, at the academy, where the emphasis remains on organizational commitment, a seemingly contradictory message emerges, where the academy atmosphere and lessons encourage collective solidary and comradery among recruits, while also reminding recruits to remain self-focused, enforcing that recruits are accountable for their actions or role in the acts of others. In response, I show how recruits appear to be socialized for, what I refer to as, caveated comradery; where recruits learn the value of collective solidarity and comradery but only as far as all recruits act with integrity and abide to the behavioral expectations of the organization.

\author{
JQCJC "Qualitative \\ Criminology," (2022) \\ Vol. 11, Iss. 1, 65-88
}

ARTICLE HISTORY

Received 4/26/2021

Accepted 7/13/2021

\section{KEYWORDS}

Training, socialization tactics, organizational commitment, Correctional

Officer Training Program

Researchers interested in socialization within correctional institutions tend to focus on the experiences of prisoners, especially their adaptation to life in prison (Clemmer, 1940; Sykes, 1958; Wheeler, 1961), rather than the experiences of correctional officers (COs) (Regoli, Poole, \& Schrink, 1979). Prisons are, for security reasons, closed to the outside world (Farnese, Bellò, Livi, Barbieri, \& Gubbiotti, 2016, p. 429). For this reason, Farnese et al. (2016) suggest new correctional employees are unable to anticipate the nuances of their occupational role or the associated organizational procedures and processes, 
despite training and the associated anticipatory socialization training provides (Merton \& Rossi, 1968). New hires enter a physically and psychologically demanding as well as uncertain work environment that is largely unknown, unless they have prior correctional experience. Thus, correctional training and the socialization processes it promotes represent a central means through which correctional workers anticipate their work routine, learn their position within the organization, and develop key occupational skills. These skills refer to occupational agency, discretion, and commitment to colleagues and the broader organization. Moreover, organizations invest tremendously in recruit and staff training, yet without an examination of socialization within a training academy, the outcomes of training, intended or not, are ambiguous. Although crucial for correctional workers and correctional agencies, correctional training, including its socialization processes, yet there is a lack of research on either how COs are socialized through their training or once working within the institution (Crouch \& Alpert, 1982). Understanding occupational socialization is invaluable for correctional service organizations as $\mathrm{COs}$, like police officers (Van Maanen \& Schein, 1977), do not depart training untouched by the experience. Training shapes each recruit to some degree and will have some effect on, for example in the case of $\mathrm{CO}$ training, attitudes toward prisoners, and their understanding of prisons.

Considering the lacunae in knowledge around how correctional training socializes COs in Canada, I draw on my participation (i.e., my socialization processes) in CTP to provide an ethnographic analysis of the formal and informal socialization processes that $\mathrm{CO}$ recruits undergo to learn their occupational role and responsibilities; my focus is not on the training content per se. The program has three stages (including a 14-week inperson component) through which federal COs in Canada are trained-and thus socialized in anticipation-for the profession. In unpacking my perceptions and experiences, I use Van Maanen and Schein (1977) theory of organizational socialization to understand the socialization process inherent to the structure of the training academy, while noting the key elements of informal socialization recruits experience.

I structure the current article such that I first briefly review the literatures on organizational and correctional socialization, $\mathrm{CO}$ culture, and organizational commitment before explaining the methods. I then present findings, with an emphasis on socialization processes as evidenced before arriving at the training academy in Stage I (and II), and once at the academy in Stage III. I conclude with recommendations for policy and practice tied to organizational socialization and its role in shaping training. 
"Qualitative Criminology" Socialization Across the Three Stages of the Correctional Service of Canada's Correctional Officer Training Program

\section{Organizational Socialization}

Emphasized by researchers examining early career experiences, organizational socialization is considered the central process through which new employees become effective organizational members (Saks \& Gruman, 2012; Becker \& Strauss, 1956; Brim, 1966; Van Maanen, 1975; Van Maanen \& Katz, 1979). Van Maanen (1975, p. 207) defines organizational socialization as "the process by which an organizational member learns the required behaviors and supportive attitudes necessary to participate as a member of an organization" (see also Cooper-Thomas \& Anderson, 2006; Louis, 1980). These processes happen throughout the course of work within an organization, from recruitment to retirement. Here, socialization refers to the informal messages taught at the academy as well as the latent lessons derived from training (e.g., firearms socialization leads to offering congratulations for accuracy, creates nervousness around the training and testing, informs attitudes toward firearms). Training and socialization then do not simply overlap considerably, they occur simultaneously, each informing and shaping the other. I unpack how I experienced socialization across the stages of CTP and how I observed other recruits' socialization during Stage III of CTP-including the institutional socialization tactics inherent to the structure of the training academy (Jones, 1986).

Organizational socialization includes employee perceptions that are often rooted in the situational definitions individuals develop, share, and learn in the workplace or, for the purposes of the current article, at the National Training Academy (Schein, 1971; Van Maanen \& Schein, 1977). Organizational socialization underpins how an individual first becomes, and then continues as, a bondable and identifiable member of an occupational group (Van Maanen \& Katz, 1979). Organizational socialization represents a setting in which individuals build and manage their occupational identity, determining their fit (and unfitness) to peers and the organization. For instance, Van Maanan and Schein (1977) found that police recruits or "newcomers" must pass through a demanding ritualized, lengthy, and formal process to develop (and show) their occupational fitness and are also under close observation from senior organizational members who are invested in how recruits progress during training. Moreover, tied to different socialization processes are diverse cognitive orientations among those who participate in such processes.

Van Maanen and Schein's (1977) theory of organizational socialization rests on a typology of six polarized socialization tactics, namely, collective versus individual; formal versus informal; sequential versus random; fixed versus variable; serial versus disjunctive (e.g., the trainer/mentor models behaviors appropriate for the occupation versus the a lack of such a role model); and investiture versus divestiture (e.g., accepting of personal attributes versus working to rid the recruit of certain qualities). Each tactic produces a 
different role orientations, degrees of ambiguity, and conflict among recruits, as well as variance in job satisfaction, commitment, and occupational leaving. Collective tactics are common learning experiences designed to standardize how recruits respond to situations and thus socialize recruits to accept the organizational standards tied to the occupational role. Conversely, individual socialization tactics allow for heterogeneity in the responses of recruits by providing unique learning opportunities (rather than standardized), which allow for more innovation in how recruits adapt to the occupational role (Van Maanen \& Schein, 1977; Van Maanen \& Schein, 1979). Relatedly, informal and formal socialization tactics, the former referring to newcomers learning separated from employees and the latter referring to newcomers learning on the job, result in diverse socialization outcomes.

Yet combined, collective and formal tactics increase the likelihood that recruits will share occupational understandings, values, attitudes, norms, and thus definitions of occupational situations. Individual and informal tactics, on the other hand, together create a space for recruits to respond to situations differently, including in innovative ways (Van Maanen \& Schein, 1977). Additional socialization tactics relate to how training content is delivered (e.g., fixed and sequential versus variable and random), the persons delivering the training content (e.g., serial versus disjunctive), and the degree of social support received at occupational entry by new employees (investiture versus divestiture), each argued to result in diverse socialization outcomes among recruits. Specifically, individual, informal, variable, random, and disjunctive socialization tactics that include divestiture, practices that Jones (1986) refers to as "individualized socialization tactics," are to correlate with innovative role orientations (p. 266). On the other hand, "institutional socialization tactics" (e.g., collective, formal, sequential, fixed, serial, and investiture tactics) are thought to result in more situational consistency in the behaviors of new employees (Jones, 1986).

For large organizations that hire numerous new employees at one time, such as the military, policing organizations, and correctional services, training programs at an "Academy" often occur prior to starting the job. These training programs are easily interpreted as instruments of organizational socialization (Jones, 1986) and invested in because training processes support employee organizational and occupational adjustment while impacting organizational attitudes and behaviors (Bauer \& Erdogan, 2012). Meta-analytical reviews show the value of organizational socialization in fostering organizational commitment and job satisfaction, while lessening role ambiguity, role conflict, and the job-leaving intention of new employees (Bauer, Bodner, Erdogan, Truxillo, \& Tucker, 2007; Saks, Uggerslev, \& Fassina, 2007). The more effective the organizational socialization processes, the more that new employees will successfully modify their actions within the organizational setting, even positively influencing longerterm career successes (Anakwe \& Greenhaus, 1999; Ashforth, Sluss, \& Harrison, 2007; 
"Qualitative Criminology" Socialization Across the Three Stages of the Correctional Service of Canada's Correctional Officer Training Program

Yang, 2008). While formally and informally training recruits to take on their occupational roles, CTP recognizes the interrelationship between socialization, commitment, and culture, topics that I address in the next section.

\section{Correctional Officer Culture and Commitment}

\section{Culture}

Underpinning organizational socialization is organizational culture; culture refers to the knowledge and information that is commonly shared by organizational members and that informs, among others, acceptable behavior processes and beliefs (Van Maanen \& Katz, 1979). In the current study, organizational culture is the knowledge that recruits receive through CTP on how to perform the CO role. This knowledge ensures the survival of the organization across time and space (Van Maanen \& Katz, 1979). Changes in organizational socialization, informed by organizational commitment, could potentially change the organizational culture and, thus, the greater organization.

Crawley and Crawley (2008) stress the importance of the occupational culture and resulting social interactions for COs. They note that "in the prison, how things are done can be as important as what is done, and occupational (that is, informal) rules and norms underpin how officers relate to their inmates, to each other, to their superiors on the wing and to their managers" (pp. 134-135). Although research on CO cultures is rather limited, the role orientations and attitudes of officers are thought to shape the occupational culture, which varies across prisons, units, and organizations, to some degree (Crewe, Liebling, \& Hulley, 2011; see also Sparks, Bottoms, \& Hay, 1996; Morrison \& Maycock, 2021). Explicitly, Crewe and his colleagues (2011) found that "attitudes do not translate into behavior in a straightforward manner. Instead, they are mediated by forms of competence and professionalism, which are themselves related to levels of experience and staffing ratios" (p. 111). Moreover, occupational culture, with its associated norms, shapes staff responses to their workspace, each other, prisoners, and, most relevantly here, new recruits.

Some scholars write of an informal masculine CO culture (Jurik, 1985), others speak to the variation between the culture among front line officers and that of middle and upper management (Farkas \& Manning, 1997), and many discuss culture in reference to officer-prisoner relationships (Halsey \& Deegan, 2017). The tenets of CO occupational culture, according to Crawley and Crawley (2008) include "a) an expectation of solidarity between members; b) suspicion; c) feelings of social isolation; and d) an emphasis on physical courage" (p. 137; see also Arnold, 2016). Solidarity among officers is thought to underpin officer safety (e.g., protecting each other in the case of an altercation), create a 
sense of comradery (e.g., a sense of family or brotherhood), and create assurances of confidentiality regarding organizational nuances (Crawley, 2004; Kauffman, 1988; Lombardo, 1981). Resonating here, Farkas (1997) found in her study of the "normative code" (i.e., informal behavioral rules) among COs, employed in two Midwestern prisons in the United States, that the "code" functions to promote solidarity among officers which helps guide officer actions and regulate behaviors.

\section{Organization Commitment}

The concept of organizational commitment refers to an affective (e.g., psychological commitment), moral (i.e., normative commitment or sense of loyalty toward the organization) and continuous (e.g., investments into the organization) attachment to an employing organization (Allen \& Meyer, 1990; Meyer, Allen, \& Smith, 1993; Meyer, Stanley, Herscovitch, \& Topolnytsky, 2002). Specifically, marking organizational commitment is employee loyalty, involvement, and the draw to remain under the organization's employ, as well as employees sharing values and an identity (Allen \& Meyer, 1990; Meyer et al., 1993; Mowday, Steers, \& Porter, 1979). Empirically, scholars examining organizational commitment describe its underpinning affective component as a relatively reliable predictor of employee commitment; affectivity translating to meaningful outcomes with extensive applied implications for the organization (e.g., reduced occupational leaving, increased employee satisfaction) (Allen, Shore, \& Griffeth, 2003; Meyer et al., 2002). Lambert, Hogan and Jiang (2008) examined the affective, moral, and continuance components of organizational commitment among correctional staff at a high-security prison in the Midwestern United States, finding that commitment impacts structuring factors within an organization, such as input into decision making, job autonomy, promotional opportunities, institutional communication, organizational fairness, job performance, and job stress (Lambert \& Hogan, 2009). More recently, staff affective commitment, Lambert and colleagues (2013a, 2013b) found, increases with effective training and socialization tactics. The authors also documented a positive relationship between burnout and continuance commitment and a negative relationship between burnout and affective commitment among correctional staff (Lambert et al., 2013a, 2013b).

Regarding new employees how the newcomer is accepted by their colleagues and their definition of their occupational role informs organizational (and thus group) commitment (Allen \& Meyer, 1990; Jones, 1986). New employees are just being introduced to the organizational culture, thus the environment is uncomfortable, and efforts are necessary toward integrating. The aforementioned institutional socialization tactics, as put forth by Jones (1986), reinforce organizational commitment, more so than individualized tactics, because they impose structure, transfer information, and promote 
"Qualitative Criminology"

consistency that collectively reduces the "problems" that come more readily with individualized socialization tactics (p. 266). Overall, organizational commitment, culture, and socialization are interconnected phenomenon, each either shaping or informing the other, often simultaneously, both in terms of how each is felt and enacted.

\section{Methods}

I draw the data for the current study from my ethnographic experience across the three stages of CTP. A key objective of the current study was to lend insight into how COs are socialized into the role of a $\mathrm{CO}$ during training and the implications of socialization for their job performance. To this end, I participated in the three stages of CTP; CSC authorized my study, and my fellow recruits were made aware of my intentions. Lasting four weeks, the first stage occurs online. The second is self-directed, realized as a series of 'homework' assignments, each to be completed before arriving at the academy for the approximately 14-week in-person component, Stage III, of CTP. The in-person component of the training involved traveling to Kingston, Ontario, living in a dorm among other recruits, and participating in all components of the training, which included instructional hours running from $8 \mathrm{am}$ to approximately $4 \mathrm{pm}$ Monday through Friday. Although my Stage I experience was largely consistent of that of other recruits, two exceptions were made during Stage III that did set me apart from my colleagues. I was able to have my phone on my person during training (if it was concealed) and had access to office spaces normally off limits to recruits. I was also distinct in that I was not there for a career as a correctional officer.

Although always an active participant, I did maintain a researcher's lens, which involved actively recognizing that all persons involved in CTP-the trainers, recruits, and so on-co-create the training experience (Charmaz, 2006). Beyond the active participation in CTP, I was also a direct observer (Snow, Benford, \& Anderson, 1986) who spent much time "hanging out" with my fellow recruits and in spaces both affiliated and not affiliated with the training or academy (Browne \& McBride, 2015). I kept detailed notes of my interactions, observations, and training content. I complemented my notes with interviews conducted with 354 recruits as part of a corresponding longitudinal study as well as interviews with academy trainers. In the current article, I focus on my field and training notes generated during Stages I and III of CTP; with an emphasis on my experiences "being there" and "hanging out". To analyze my data, I read through my field notes for themes, organizing notes by theme rather than chronology, I then reflected on my experiences, and reviewed the training content against both experiences and field notes. I drew upon salient themes emergent across field notes, and than informed the themes with my own reflections from my experiences as well as the words other recruits used to discuss their experiences during the ethnography. I also discussed my 
Rosemary Ricciardelli

experiences with select colleagues familiar with prison work to help me probe my experiences more deeply, creating a space for critical reflection.

\section{Findings}

\section{Stage 1: Anticipatory Socialization}

Prior to arriving at the National Training Academy, recruits must pass and complete a series of online training modules within the span of four weeks, referred to as CTP Stage 1. CSC sends recruits "Joining Instructions" (CSC, CTP Stage 1, July 2018), welcoming and congratulating recruits for their "success in meeting most of the required screening requirements, selections and evaluation for this stage of the process" and then encourages recruits to "continue with your goal in working for CSC and participating in this training program with integrity and perseverance" (p. 4). Accompanying Stage 1 is an onslaught of nerves, temporary excitement, and some pride in being successful in the process (e.g., passing the interview, assessments); each emotion in some way priming the recruit for their socialization by underpinning their approach to the training. Stage I represents a recruit's introduction to the actual training content and nuances of the occupation from a legal and safety/security standpoint-it is the start of recruit socialization using institutional socialization tactics (see Jones, 1986) into the CO/COR role. Here, I draw attention to three elements of recruit socialization and the associated lessons learned as introduced in CTP Stage I and delivered using collective socialization tactics (Van Maanen \& Schein, 1977). The elements are: i) module content (i.e., the vast module content with an emphasis on history, policies, and legalities), ii) commitment (i.e., the necessity of commitment for success), and iii) stress (e.g., testing, completing Stages 1 and 2 on time).

\section{Module Content}

Regarding module content, recruits must complete 10 courses within a four-week period. Content includes a comprehensive introduction to correctional services in Canada, including changing interpretations of punishment and prison and a thorough review of law and policy. Next, modules cover the role and responsibilities of $\mathrm{COs}$, the engagement and intervention model (which informs officer discretion and decision-making, Ricciardelli, forthcoming), workplace concerns, suicide prevention and self-injury, substance abuse, ethical issues, and insight into the social worlds of prisoners. The introduction to the training material is not gradual. Recruits launch into a seemingly overwhelming mass of material (that hyperlinks to even more required content). The modules' length, and at times dated graphics, makes the feat of completing the sessions within a month feel virtually impossible. Moreover, the feeling does not dissipate with time, rather I found it 
"Qualitative Criminology"

intensifies as the material one is responsible for grows and the implications of such responsibility (e.g., preserving life) become more substantiated by the emphasis on justifying and explaining actions engaged in as a CO. Nevertheless, particularly reading the Commissioner Directives, policies, and the history of CSC and correctional services in Canada made me feel, at least temporarily, very knowledgeable about correctional practices including what is versus is not possible in terms of confidentiality, need-to-know specifications, and security related policies. Thus, module content informally conveys the seriousness of the occupational work, but formally ensures an initial grasp of the job responsibilities, organizational and hierarchical command structure, and policies shaping the care, custody, and control of prisoners. The material reinforces the public safety element of the occupation and the positioning of COs as Peace Officers.

\section{Commitment}

Recruits must be fully committed, disciplined, and dedicated to the training if they are to learn all the material within the allocated time. Basically, recruits are being socialized in the expected work ethic. They are to participate in their learning (i.e., continuous commitment), demonstrate their loyalty by completing the work (e.g., moral commitment), and psychologically invest in the process (e.g., affective commitment) to be successful (see Allen \& Meyer, 1990; Meyer et al., 1993; Meyer et al., 2002). Compounding this was that staying focused was not easy at times, particularly after a full day of work accompanied by family responsibilities-something shared by many recruits who tend to be employed (elsewhere) during Stage I and II, have families, are anticipating the career change, and trying to learn all the material in the modules. I struggled significantly with the retention and the sheer volume of material to read, repeatedly feeling stressed about if I was going to finish the modules on time. Here, the intersection of diverse stressors is inevitable as, for example, the commitment and discipline required to complete all the modules creates stress that the testing (see below) exacerbates. Creating a pressure infused environment feels largely instrumental in the socialization processes. Socialization and training work together, operating simultaneously, and providing a consistent message about the need for recruits to be affectively, morally, and continuously committed (Allen \& Meyer, 1990; Meyer et al., 1993; Meyer et al., 2002).

\section{Stress}

During Stage 1, CSC introduces recruits to the stressors of testing. Modules 2, 6, 7, 8, and 10 have testing, however, recruits are scored, receive their grade at the end of the test, and can redo the tests repeatedly to optimize (or until satisfied with) their score. Because of the testing, my focus was largely on key points, take home messages, and repeated information as I focused my studies on the material I deemed most likely to be 
on the tests (i.e., material that lends itself well to examination). The final test in Stage 1, written in bold red font and visible immediately once logged into the system, is by far the most intimidating test. CSC clearly states that recruits have only one attempt to pass (i.e., a score of at least 70\%) and they must pass to move on to Stages II and III. Testing felt like a key component of socialization even before arriving at the academy, adding pressures that, as will be discussed, create a tense environment at times that recruits must learn to manage. According to some recruits and trainers, testing is a form of anticipatory socialization (Merton, 1972) serving to prepare recruits for the more tense moments that come with the career choice. Stage II, an independent series of work assignments that one must commit to completing prior to arriving for Stage III, includes intensive work but without testing.

\section{Stage III: Socialization Tactics and Organizational Commitment}

Reflecting on Van Maanen and Schein's (1979) typology, the training environment at the academy uses formal (e.g., recruits are separated from employees), fixed (e.g., a timetable is adhered to at CTP) and sequential (e.g., recruits are being informed about the occupational role), collective (e.g., common learning experiences) and serial (e.g., trainers are all experienced COs) socialization tactics. The expectation is for the trainers at the academy to perform as role models for the recruits, while the academy socializes recruits in a manner that encourages standardized responses when approaching situations and promotes organizational commitment.

We quickly learned the academy (on day one of my CTP experience, June 2019) had 23 trainers at the rank of Correctional Officer III (CXIII), meaning each is an experienced officer who qualified to train new recruits (formal and serial tactics, Van Maanen \& Schein, 1977). The atmosphere includes nervous energy and much anticipation about what is next to come, curiosity about trainers, and interest in fellow recruits. Of the recruits in my cohort, three returned after not completing CTP on their prior attempt. Although training occurs Monday-to-Friday with class starting at 8am and ending around $4 \mathrm{pm}$, trainers may release recruits early or hold them late as a group depending on if the required material is covered and the degree of uptake of the material among classmates (e.g., fixed tactics, Van Maanen \& Schein, 1977).

At CTP, lateness is unacceptable such that if a recruit is repeatedly tardy the academy may impose consequences. If a recruit is to miss class, the instructors require immediate notification. Moreover, CSC will formally release a recruit for failing to comply or violating the policies and practices of the organization (e.g., cell phones are not permitted in class, taking or posting photos of the facilities, staff, or other recruits unless authorized is not allowed). Recruits' are clearly told "Don't blog about your experiences 
"Qualitative Criminology"

and don't blog about your thoughts," with trainers advising recruits to treat the academy as a prison and to treat everything "as real." The omnipresent surveillance of recruits is apparent as trainers remind recruits that they are constantly under observation, including by the trainers who themselves are invested in their progress throughout the 14-week job interview (e.g. collective tactics, Van Maanen \& Schein, 1979). This is a way to prepare recruits, intentionally or not, for the fact that they too are surveilled in prison work; they are public servants and officers of public safety.

Like during Stage I, module content, commitment, and stress via testing are key components to the CTP experience. Recruits immediately feel the emphasis trainers and CSC more broadly place on organizational and occupational commitment. CTP begins with a review of the recruit code of conduct. Here, trainers outline expected, appropriate, and inappropriate recruit behaviors and expectations around trainer-recruit relationships, as well as instructs recruits to memorize the CSC mission statement-again confirming recruit commitment to the training and to adhering to CSC standards. Psychological, moral, and affective commitment underpin the reminder recruits receive, in the form of a black business card inscribed with the names of each federal $\mathrm{CO}$ who died in the line of duty, that some COs have given the ultimate sacrifice. Trainers instruct recruits to place the card behind their IDs on their lanyard, so they carry these names on their person during training. The symbolism behind the card and its placement reinforces to recruits the commitment expected for correctional work. Organizational commitment is reinforced each time recruits sign or swear the CTP attestation; where they attest to be physically and mentally able to proceed, at the start of CTP and prior to each strike-able test.

Institutional Socialization Tactics, Standardized Responses, and Individualized Emphasis

In Stage III, recruits continue their socialization into the occupational culture; they learn the information commonly shared among members of the organization that determines expected and acceptable actions for those occupying the occupational role (Van Maanen \& Katz, 1979). Emergent theme analysis reveals that the material taught, the lessons learned, and the general message from trainers (and academy) is that personal integrity is most valuable and a recruit should never compromise their behavior, which should demonstrate their prioritizing of their moral and affective commitment to the organization and occupational work (Allen \& Meyer, 1990; Meyer et al., 1993; Meyer et al., 2002). Contrary to interpretations of peace officers as embedded in cultures that promote comradery and "having each other's backs" at all costs, the central informal and formal message at the academy delivered to the recruits was that the commitment to the occupation included not acting in ways that violated policies, laws, or that were unethical. Even in the most formal of settings, trainers remind recruits that "a friend" would not place them in a compromising position (asking to ignore inappropriate acts, etc.). 
Van Maanen and Katz (1979) found that early periods when embarking on a new career are important socialization periods, specifically in the early days new employees feel most vulnerable, they are in an uncomfortable organizational culture, and thus most susceptible to learning the perspectives of employees with longer tenure (and thus the organizational culture). Moreover, they note that senior employees, like the trainers in the current study, are more likely to reprimand or call out new employees (in this case, new recruits) if their behaviors stray from that which is expected. Specifically, Van Maanen and Katz (1979, p. 49) argue that "perceptual (and, perhaps, behavioral) deviance is dealt with most stringently during a patrolman's initiation into the organization" (see also Schein, 1971). Similar lessons are enforced among recruits, however the message is that, using the words of Van Maanen and Katz (1979), "deviance" is not to be tolerated across, among, or between recruits and "deviance" includes acting in ways that are not within the expected behaviors as put forth by CSC. During the earlier weeks, particularly the early days, of Stage III, trainers frequently and reliably call out recruits for their behaviors. Of note, two phenomena are at play here, first for some recruits the frequency of less desirable behaviors decrease as the academy socializes recruits in behavioral norms (e.g., recruit behaviors become more organized, prepared, and standardized). Second, trainers become more accustomed to particular recruit's behaviors and thus less frequently draw attention to correcting them (e.g., the recruit does not change their behavior despite trainers' efforts, which can be frustrating to the cohort and trainers, who may strive to enforce behavioral change through more formal sanctions).

To exemplify, in Stage III, multiple times when a "deviant" behavior occurred reprimand followed, at times for the specific recruit and at other times for the many within the cohort or a combination of such. Regarding specifics, trainers reprimand recruits for behaviors that fell out of line with expected behavioral expectations (i.e., pressed uniform, shined shoes, organized dorm room). If there was evidence that supported more serious deviance had occurred and a recruit failed to take accountability, there was the possibility that other recruits will be asked to confirm the recruits' engagement in the deviant action or not. In essence, recruits may feel pitted against each other in cases of possible recruit misconduct. The clear message was not simply an emphasis on comradery and solidarity but instead was about acting with integrity, morally, and, thus, demonstrating organizational commitment.

The messaging at the academy both ensures individualization among recruits and reinforces standardization in responses while creating bonds between recruits. The message promotes the expectation of solidarity among recruits, a solidarity contingent on individual actions being in line with CSC expectations and neither compromising their safety or job nor that of their colleagues. To this end, the expected and appropriate 
"Qualitative Criminology" Socialization Across the Three Stages of the Correctional Service of Canada's Correctional Officer Training Program

behavior is to confirm (or report) the negative behaviors of others, an expectation that falls far from enacting the idea of a culture of solidarity and comradery.

\section{Institutional Socialization Tactics, Standardized Responses, and Collective Emphasis}

Navigating the pressures, tensions, and stressors that the testing/strike system imposes strengthens and reinforces bonds between recruits. The academy environment is highpressure and bonds are likely to develop between recruits (or some recruits) in each cohort of CTP over their 14-week experience. In some ways, similar to the pressures placed on the required final Stage I test, in Stage III, recruits are introduced to a strike system, where each failed test (i.e., a score of under 70 percent) constitutes one "strike." Depending on who one speaks with, the pressure imposed by the strikes is either intentional, designed to reflect the tensions in prison work, or is an unintended consequence of the stress of CTP. No matter the origin, the environment is quite tense at times and stress weaves itself into the fabric of the experience through the testing.

The strike system, intentionally or not, creates dependence between recruits-at minimum pairs of recruits. Testable actions often require two recruits to be performed (e.g., arrest and control; self-defense). Recruits then rely on each other for at least two practical reasons: to practice for testing, and when performing their actual tests. Given recruits can help each other when testing in pairs versus when tested individually, the dependence is even more important; a trusted colleague is an invaluable support when testing. There are over 50 strikes that recruits can acquire, each tied to an examination of a specific series of skills and knowledge (e.g., law and policy, arrest and control, assorted searches). There are modules and lessons that are not tested within the strike systems, including decision based training scenarios (DBTS), communication and deescalation skills, and Advanced Mental Strength and Conditioning (AMStrength). If a recruit earns three strikes (i.e., three test scores under 70 percent, or less than $100 \%$ on the $40 \mathrm{~mm}$ launcher), the recruit has failed to complete CTP and, in consequence, must depart from the academy. The test/re-test policy provides a second opportunity for recruits to pass a test after a strike, however, if the recruit's score is less than 70 percent on the retest the academy will release the recruit-with an exception for firearms testing (discussed below). The omnipresent threat of earning a strike not only affects recruits as they stress not passing a test, but also creates bonds between recruits as they study and train to pass each test together; ironically, testing is an intersection of individual and institutional socialization tactics.

The first strike-able test occurs on day 2 of CTP and is the topic of extensive and immediate discussion as recruits arrive at the academy. Study sessions fill the first few evenings at the academy, like most other evenings, and the air is always thick with 
tension, a quite contagious nervous energy, before testing. My field notes reveal anxious discussion about testing on day one, with a recruit exclaiming "Jesus," and another asking about rates of failure, which was not a question received favorably by either trainers or recruits.

A common area where recruits earn strikes is firearm modules. Here, recruits can earn two strikes in one day (there are often three sequential strike-able tests and each recruit must pass the first (i.e., theory) to move on to the second (firearm manipulation) and then third (qualification exam). If a recruit earns a strike on the manipulations or applied firearm test, if it is not the recruit's third strike, the recruit undergoes an additional 2.5 hours of training with instructors and completes a remedial retest. It is possible to earn another strike at the first remedial, which if the recruit is only at two strikes, they can complete a third remedial test after eight hours of focused firearm training. The retest with remedial policy is only for firearm qualification testing. The practice with firearm theory testing follows the same policy as all other tests (i.e., failing the test acquires the recruit a strike, failure on the re-test results in a recruit being released from CTP). As a researcher, I regularly heard of people earning strikes on the $9 \mathrm{~mm}$ pistol qualifications test (including those who, in consequence, were released). A common occurrence was a recruit missing one of the four "headshots" with pistol, which is exactly what I did to earn a strike.

I found shooting exceptionally stressful on testing days because: i) a recruit (who is often a friend) may be sent home, and ii) the possibility of being awarded a strike was a consuming thought. A recruit can be awarded a strike at any time (particularly given testing is more frequent as graduation approaches) and thus recruits are sent home from Stage III sometimes immediately before graduation (after the mess dinner). I could feel the tension in the air, I was overly empathetic, and found myself stressing my own ability to demonstrate my learning (the trainers were phenomenal and I did not want to disappoint) during firearms testing. I recall feeling overwhelmed rather than comfortable, overthinking everything and increasingly feeling consumed by anticipation. I also relied on two fellow recruits to check and fix my manipulations, recalling that frustratingly my brain was functioning as a sieve given my nervousness. Of course, I was not going to be a correctional officer, I had a job, and I could not be sent home for strikes because I was first and foremost a researcher. I did not have the same stress as the recruits but I felt stress and could only imagine how my colleagues felt. I saw tears, frustration, and stress around the processes of learning, testing, and preparing for firearms during CTP. The strike system, intended or not, adds to the intense environment while also building bonds between recruits who are supporting each other as they try to pass each test. Receiving a strike is stressful and trainers remind recruits that composure is vital to the $\mathrm{CO}$ job despite personal feelings. I felt bonded to the people with whom I completed remedial 
"Qualitative Criminology"

training. We were a small group of four within the cohort. I valued their support as well as that of the trainers who I felt truly believed I could pass the testing when I was ridiculously anxious and navigating self-doubt. It is in these situations, recruits entirely solidify their relational bonds with other recruits-even temporarily.

The release process itself also solidifies bonds between those who remain and instills the "realness" of the interview process, being integral to the institutional socialization tactics. After the academy releases a recruit from CTP, either for a strike or ethics, values, and integrity (see Ricciardelli, forthcoming), two instructors immediately accompany the recruit back to their residence and stay with the recruit until they have left the academy space. Trainers reclaim all CSC property while the recruit packs under the two trainers' supervision before heading home by car, train, or plane. If the recruit cannot depart until the next day (due to flight scheduling, for example) they stay at a hotel, not in the residences, and there is often no formal contact or opportunity for contact with the recruit.

Everything about the release process, albeit for whatever reason, reinforces the bonds between the recruits who remain but also creates individualized tensions. The process reinforces comradery as people work together to pass tests, even helping each other during testing, but reminds everyone that they are individuals in their job interview. The shared high-pressure experience reinforces bonds but simultaneously, the pressure can create conflict between recruits. A caveated comradery is learned, which perhaps shed light on researchers' finding that among COs colleagues are one of the most pronounced sources of occupational stress (Ricciardelli, 2019; Ricciardelli \& Carleton, 2021).

\section{Discussion}

A central function of any training program, intentional or not, is to socialize recruits toward becoming effective organizational members - to "fit into the organization" as both bondable and identifiable members of the occupational group (Franses et al., 2016, p. 430). The training of recruits starts before they arrive at the academy during the first stages of CTP where recruits are inundated with context and responsible for learning vast quantities of material about the legalities and policies underpinning institutional correctional work. Socialization, different from training but related, is the lessons learned beyond the module content. Such lessons continue through CTP Stage III but, in Stage III, lessons engender an applied component-each is enacted as much as taught in the classroom. Verifying the value of both aspects of learning is how strike-able testing is placed after both classroom learning and applied learning (e.g., in class, on the range, in the gym, in mock cells). However, a challenge for trainers is how to drive home the 
importance of the material that is not directly or easily testable (e.g., communication and de-escalation skills), as recruits tend to direct most of their energy during training to learning the material on strike-able tests (which is also what I did).

Thematic reflection reveals that even before arriving at the academy, the pressures tied to testing and the module content reinforce organizational commitment. Moreover, it is at the academy, where emphasis remains on organizational commitment, that a seemingly contradictory message emerges, where the academy atmosphere and lessons encourage collective solidary and comradery among recruits, while also reminding recruits to remain self-focused, enforcing that each recruit is accountable for their actions or role in the acts of others. Recruits are both to be bonded and split, on the one hand ready to protect each other, on the other, never to turn a blind eye toward concerning behaviours. In response, recruits appear to be socialized for, what I refer to as, caveated comradery; where recruits learn the value of collective solidarity and comradery but only as far as all recruits act with integrity and abide to the behavioral expectations of the organization. What results is a slight lacing of mistrust among colleagues that nags at the level of solidarity among a cohort. In an environment, that breeds hypervigilance and surveillance as characteristics of employees, it is not surprising that it also inadvertently socializes officers to be reserved with their trust.

Although caveated comradery is taught, the pressure infused training environment produces strong bonds between recruits, perhaps stronger than intended, in focusing on both the individual recruit (e.g., ensuring each recruit learns the skill under study) and the greater collective (e.g., moving the cohort through material as a group, encouraging recruits to help each learn, reliance on each other when testing). The strike system, for instance, creates undeniable pressures as any recruit can earn a strike or the required three that result in release. As noted, in the training environment, to do well on tests recruits do rely on each other. Thus, despite the intended message of caveated comradery, bonds emerge, not always across an entire cohort but at least between pairs of recruits.

Jones (1986) found that individualized socialization tactics correlate with ambiguity and innovative approaches among employees and institutional socialization tactics correlate with standardized approaches among employees. The solidary encouraged during training is likely affected by experiences when recruits are deployed to prisons as COs; here, they are open to socialization processes despite if socialization tactics are investiture (e.g., results in more innovative responses) or divestiture (e.g., results in more standardized responses). Future research that examines how CSC COs are onboarded into institutional work, particularly if practices follow institutional or individual socialization tactics, is warranted. Such an area of examination would help CSC and other 
"Qualitative Criminology"

organizations using training academy models understand how their employees apply, or if their employees apply, their training and its nuance once within the organization. Particularly of significance is understanding how CSC's emphasis on values, ethics, and integrity is onboarded into the institutions, which may lend greater insight into CO cultures or public safety cultures more broadly—areas requiring further investigation.

The occupational culture during training promotes organizational commitment, in both how material is taught and what material is taught (see Crawley \& Crawley, 2008). The construction of an occupational culture rooted in employee integrity is foundational to the lessons of the academy; verifying that CSC recognizes that occupational culture shapes how COs respond to their work environment and all persons within that space. Thus, key to the academy is the construction of the occupational culture the organization desires to be upheld within each prison-however, its success in perpetuating such an occupational culture can only be unpacked with focused work on employee experiences of their occupational culture post deployment. Researchers have long noted that occupational cultures vary across prisons, units, and organizations (Crewe et al., 2011; see also Sparks et al., 1996).

Recruits learn the value of keeping their composure during testing, when receiving test scores, and throughout training. Said socialization is key because failing to stay composed when prompted by a prisoner, colleague, or management can compromise staff safety when in the institution. Further investigation into composure and what composure represents in $\mathrm{CO}$ work is warranted as it remains an understudied area in prison scholarship and is perhaps more complex, beyond impression management and presentation of self (Goffman, 1968), due to the physiological and psychological components necessary for composure.

I note that my study is limited. For example, I did not study or participate in onboarding (or enter the field as a CO). I only completed 10 of the 14 weeks of Stage III training for diverse methodological reasons (e.g., intending to experience more than one cohort of CTP, to complete primary worker training) that have yet to come fruition due to the COVID-19 pandemic. In addition, as with all qualitative research, I suggest caution and encourage replication (rather than trying to generalize from the findings).

\section{Implications}

The current study has implications for qualitative criminology, specifically revealing how ethnographic study can shed light on informal and formal processes occurring within organizations. Taking Van Maanen and Schein's (1979) typology of socialization tactics as a starting point, the structure of the National Training Academy, as well as all stages 
of CTP, teaches standardized ways of responding to situations and performing occupational responsibilities among recruits. The training environment, according to the typology uses serial and collective socialization tactics within its training practices, while having trainers keep close surveillance over the behaviours of recruits. The outcome than, theoretically, is the reproduction of the organizational culture. The organizational culture being reproduced encourages collective learning, solidarity, and comradery, however it does so with a caveat; that each recruit behaves how CSC expects them to behave-with integrity, values, and ethics (see Ricciardelli, forthcoming; Correctional Service Canada, 2017,2018 ). Thus, the resulting message is a reconstitution of CO solidarity that only includes those who are fully adherent and abiding to the organizational mission thus inferring a slight lack of trust of colleagues.

Implications for policy and practice are rooted in how, unpinning both individualized and collective training practices as well as institutional socialization tactics is, the value placed on the affective, moral, and continuous elements of organizational commitment, each reinforces that recruits are psychologically committed, organizationally loyal, and invested. Recruit socialization and training encourages solidarity among recruits, insofar as each recruit's actions are in line with organizational behavioral expectations. It is in this way that a seemingly contradictory message also emerges during training, specifically, the emphasis on building bonds between recruits-the collective solidarity and comradery-conflicts with the simultaneous pressure for each recruit to surveil each other, which pushes individualism. The surveillance and distrust that such practices unintentionally promote then undermines the solidarity within the cohort. Thus, despite the intention toward collectivity, recruits are to focus on their self and personally learn to succeed in the interview, to prioritize organizational commitment through personal investment and loyalty, despite the structures encouraging collective solidarity and shared learning across recruits. Organizations, however, must confirm if this is their intended messaging or a latent outcome of training.

I further ponder if onboarding corresponds or collides with the largely institutional socialization tactics of the training academy and how this impacts training practices and processes. Training and early days of employment are particularly important for new employee socialization; organizations need to invest effort into understanding how their employees are onboarded into the organizations, confirm what messages CSC intends to send to new employees, and then to ensure their intended messages, including orientations toward prisoners and degree of cynicism that emerges, are enacted through onboarding. 
"Qualitative Criminology" Socialization Across the Three Stages of the Correctional Service of Canada's Correctional Officer Training Program

\section{Conclusion}

Within the context of CTP, the tenants of the occupational culture recruits are socialized within includes the emphasis on solidary, as caveated, but also includes a focus on organizational commitment, including commitment toward following procedures as learned. During training, recruits learn strategies, for instance when to highlight they are on probation to avoid acting counter to training, to help practice their lessons as taught and to avoid falling into established but different ways of performing their occupational responsibilities. The standardization in lessons at the academy serves to reproduce an intended $\mathrm{CO}$ culture that evokes commitment and integrity, strength of character, and values solidarity. Lacing training is anticipatory socialization as training accounts and prepares recruits for the challenges they may face enacting their lessons when in the institution. Thus, the potential for a clash of cultures between that in which recruits are socialized in training versus once in the institution is real, and, again, an area of further inquiry. Particularly if the unintended consequence is a slight lacing of distrust across colleagues who are to be hypervigilant. The commitment learned in training promotes organizational loyalty, involvement, and fuels the desire to succeed (i.e., graduate from CTP) - to become a $\mathrm{CO}$ and embrace the identity of peace officer. To this end, to understand longer-term training outcomes tied to the perpetuation of occupational culture and the impacts of culture on CO identity, loyalty, and desire to maintain the occupation, future researchers may wish to examine how the prison environment (e.g., prisons with incidents, programing) informs the morale and comradery among COs. For instance, is morale or comradery higher in busier environments? How is this affected by training, occupation tenure, or ability to trust? Moreover, are institutional and academy cultures consistent or similar? How do occupational cultures vary across institutions and units and what factors inform the diversities in culture? Such knowledge can further inform training efforts toward the promotion of the intended and desired cultural objectives and occupational climate among staff.

\section{References}

Allen, D. G., Shore, L. M., \& Griffeth, R. W. (2003). The role of perceived organizational support and supportive human resource practices in the turnover process. Journal of Management, 29(1), 99-118.

Allen, N., \& Meyer, J. P. (1990). Organizational socialization tactics: A longitudinal analysis of links to newcomers' commitment and role orientation. Academy of Management Journal, 33(4), 847-858. 
Anakwe, U. P., \& Greenhaus, J. H. (1999). Effective socialization of employees: Socialization content perspective. Journal of Managerial Issues, 11(3), 315-329.

Arnold, H. (2016). The prison officer. In Y. Jewkes, B. Crewe, \& J. Bennett (Eds.), Handbook on Prisons (2nd ed., pp. 265-284). Abingdon: Routledge.

Ashforth, B. E., Sluss, D. M., \& Harrison, S. H. (2007). Socialization in organizational contexts. In G.P. Hodgkinson \& J.K. Ford (Eds), International Review of Industrial and Organizational Psychology (pp. 1-70). New Jersey: John Wiley \& Sons, Ltd.

Bauer, T. N., Bodner, T., Erdogan, B., Truxillo, D. M., \& Tucker, J. S. (2007). Newcomer adjustment during organizational socialization: A meta-analytic review of antecedents, outcomes, and methods. Journal of Applied Psychology, 92(3), 707-721.

Bauer, T. N., \& Erdogan, B. (2012). Organizational socialization outcomes: Now and into the future. In C. R. Wanberg (Ed.), The Oxford handbook of organizational socialization (pp. 97-112). Oxford: Oxford University Press.

Becker, H. S., \& Strauss, A. L. (1956). Careers, personality, and adult socialization. American Journal of Sociology, 62(3), 253-263.

Brim, O. G. (1966). Socialization through the life cycle. In O. G. Brim \& S. Wheeler (Eds.), Socialization after Childhood. New York: Wiley.

Browne, B., \& McBride, R.-S. (2015). Politically Sensitive Encounters: Ethnography, Access, and the Benefits of "Hanging Out". Qualitative Sociology Review, 11, 34-48.

Charmaz, K. (2006). Constructing Grounded Theory. London: Sage Publications Ltd.

Clemmer, D. (1940). The prison community. Boston: Christopher Publishing.

Cooper-Thomas, H. D., \& Anderson, N. (2006). Organizational socialization. Journal of Managerial Psychology, 21 (5), 492-516.

Correctional Service Canada. (2017). Values and Ethics Participant Manual Ottawa: Correctional Services Canada.

Correctional Service Canada. (2018). Commissioner's Directive 001. Mission, Values and Ethics Framework of the Correctional Service of Canada. Ottawa: Government of Canada Retrieved from https://www.csc-scc.gc.ca/acts-and-regulations/001-cd-en.shtml 
"Qualitative Criminology"

Crawley, E. (2004). Emotion and performance: Prison officers and the presentation of self in prisons. Punishment \& Society, 6(4), 411-427.

Crawley, E., \& Crawley, P. (2008). Understanding prison officers: Culture, cohesion and conflict. In J. Bennett, B. Crewe, \& A. Wahidin (Eds.), Understanding prison staff (pp. 134152). Abingdon: Routledge.

Crewe, B., Liebling, A., \& Hulley, S. (2011). Staff culture, use of authority and prisoner quality of life in public and private sector prisons. Australian \& New Zealand Journal of Criminology, 44(1), 94-115.

Crouch, B. M., \& Alpert, G. P. (1982). Sex and occupational socialization among prison guards: A longitudinal study. Criminal Justice and Behavior, 9(2), 159-176.

Farkas, M. A. (1997). The normative code among correctional officers: An exploration of components and functions. Journal of Crime and Justice, 20(1), 23-36.

Farkas, M. A., \& Manning, P. K. (1997). The occupational culture of corrections and police officers. Journal of Crime and Justice, 20(2), 51-68.

Farnese, M. L., Bellò, B., Livi, S., Barbieri, B., \& Gubbiotti, P. (2016). Learning the ropes: the protective role of mentoring in correctional police officers' socialization process. Military Psychology, 28(6), 429-447.

Goffman, E. (1968). The Presentation of Self in Everyday Life. New York: Penguin.

Halsey, M., \& Deegan, S. (2017). In search of generativity in prison officer work: Balancing care and control in custodial settings. The Prison Journal, 97(1), 52-78.

Jones, G. R. (1986). Socialization tactics, self-efficacy, and newcomers' adjustments to organizations. Academy of Management Journal, 29(2), 262-279.

Jurik, N. C. (1985). Individual and organizational determinants of correctinal officer attitudes toward inmates. Criminology, 23(3), 523-540.

Kauffman, K. (1988). Prison officers and their world. Cambridge, M.A.: Harvard University Press. 
Lambert, E. G., \& Hogan, N. (2009). The importance of job satisfaction and organizational commitment in shaping turnover intent: A test of a causal model. Criminal Justice Review, 34, 96-118.

Lambert, E. G., Hogan, N. L., \& Jiang, S. (2008). Exploring antecedents of five types of organizational commitment among correctional staff: It matters what you measure. Criminal Justice Policy Review, 19(4), 466-490.

Lambert, E. G., Kelley, T., \& Hogan, N. L. (2013a). The association of occupational stressors with different forms of organizational commitment among correctional staff. American Journal of Criminal Justice, 38(3), 480-501.

Lambert, E. G., Kelley, T., \& Hogan, N. L. (2013b). Hanging on too long: The relationship between different forms of organizational commitment and emotional burnout among correctional staff. American Journal of Criminal Justice, 38(1), 51-66.

Lombardo, L. X. (1981). Guards imprisoned: Correctional officers at work. Elsevier New York.

Louis, M. R. (1980). Surprise and sense making: What newcomers experience in entering unfamiliar organizational settings. Administrative Science Quarterly, 25(2), 226-251.

Merton, R. K. (1972). Insiders and outsiders: A chapter in the sociology of knowledge. American Journal of Sociology, 78(1), 9-47.

Merton, R. K., \& Rossi, A. K. (1968). Contributions to the Theory of Reference Group Behavior. In R. K. Merton (Ed.), Reading in reference group theory and research (pp. 215-248). New York, NY: The Free Press.

Meyer, J. P., Allen, N., \& Smith, C. A. (1993). Commitment to organizations and occupations: Extension and test of a three-component conceptualization. Journal of Applied Psychology, 78(4), 538.

Meyer, J. P., Stanley, D. J., Herscovitch, L., \& Topolnytsky, L. (2002). Affective, continuance, and normative commitment to the organization: A meta-analysis of antecedents, correlates, and consequences. Journal of Vocational Behavior, 61(1), 2052. 
"Qualitative Criminology"

Morrison, K., \& Maycock, M. (2021). Becoming a Prison Officer: An Analysis of the Early Development of Prison Officer Cultures. The Howard Journal of Crime and Justice, 60(1), 3-24.

Mowday, R. T., Steers, R. M., \& Porter, L. W. (1979). The measurement of organizational commitment. Journal of Vocational Behavior, 14(2), 224-247.

Regoli, R. M., Poole, E. D., \& Schrink, J. L. (1979). Occupational socialization and career development: A look at cynicism among correctional institution workers. Human Organization, 38(2), 183-187.

Ricciardelli, R. (2019). Also serving time: Canadian provincial and territorial correctional officers. Toronto: University of Toronto Press.

Ricciardelli, R. (Forthcoming). Informing correctional officer discretion: A co-response model and the legal vulnerabilities inherent to prison work. The Prison Journal.

Ricciardelli, R., \& Carleton, R. N. (2021). A qualitative application of the Job DemandControl-Support (JDCS) to contextualize the occupational stress correctional workers experience. Journal of Crime and Justice, 1-17.

Saks, A. M., \& Gruman, J. A. (2012). Getting newcomers on board: A review of socialization practices and introduction to socialization resources theory. In C. Wanberg (Ed.), The Oxford handbook of organizational socialization (pp. 27-55). Oxford: Oxford University Press.

Saks, A. M., Uggerslev, K. L., \& Fassina, N. E. (2007). Socialization tactics and newcomer adjustment: A meta-analytic review and test of a model. Journal of Vocational Behavior, 70(3), 413-446.

Schein, E. H. (1971). The individual, the organization, and the career: A conceptual scheme. The Journal of Applied Behavioral Science, 7(4), 401-426.

Snow, D. A., Benford, R. D., \& Anderson, L. (1986). Fieldwork Roles and Informational Yield: A Comparison of Alternative Settings and Roles. Urban Life, 14(4), 377-408.

Sparks, R., Bottoms, A., \& Hay, W. (1996). Prisons and the problem of order. Oxford: Clarendon. 
Sykes, G. M. (1958). The society of captives. Princeton: Princeton University Press.

Van Maanen, J. (1975). Police socialization: A longitudinal examination of job attitudes in an urban police department. Administrative Science Quarterly, (20)2, 207-228.

Van Maanen, J., \& Katz, R. (1979). Police perceptions of their work environment: an exploratory study into organization space and time. Sociology of Work and Occupations, $6(1), 31-58$.

Van Maanen, J., \& Schein, E. H. (1977). Toward a theory of organizational socialization (No. 960-77). Massachusetts Institute of Technology, Sloan School of Management, 89 pages.

Van Maanen, J. , \& Schein, E. H. (1979). Toward a theory of organizational socialization. In B. M. Staw (Ed.), Research in organizational behavior (pp. 209-264). Greenwich, CT: JAI.

Wheeler, S. (1961). Socialization in correctional communities. American Sociological Review, 26(5), 697-712.

Yang, J.-T. (2008). Effect of newcomer socialisation on organisational commitment, job satisfaction, and turnover intention in the hotel industry. The Service Industries Journal, 28(4), 429-443.

\section{Contributor}

Rosemary Ricciardelli is Professor of Sociology at Memorial University. Elected to the Royal Society of Canada, her research centers on evolving understandings of gender, vulnerabilities, risk, and experiences and issues within different facets of the criminal justice system.

\section{Funding}

ClHR grants: 440140, 411385, 441387. 